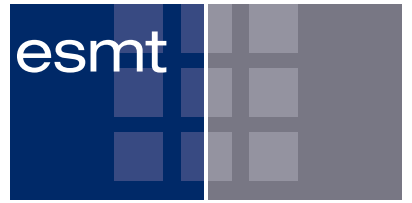

December 1, 2009

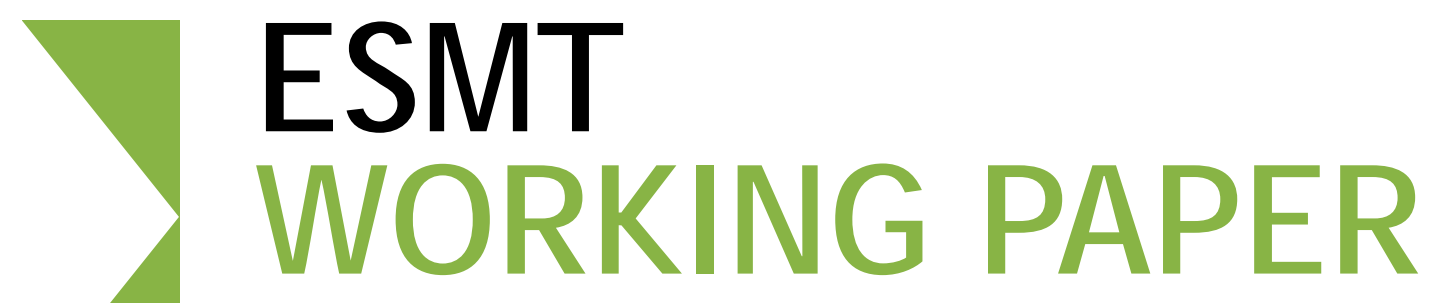

ESMT No. 09-007

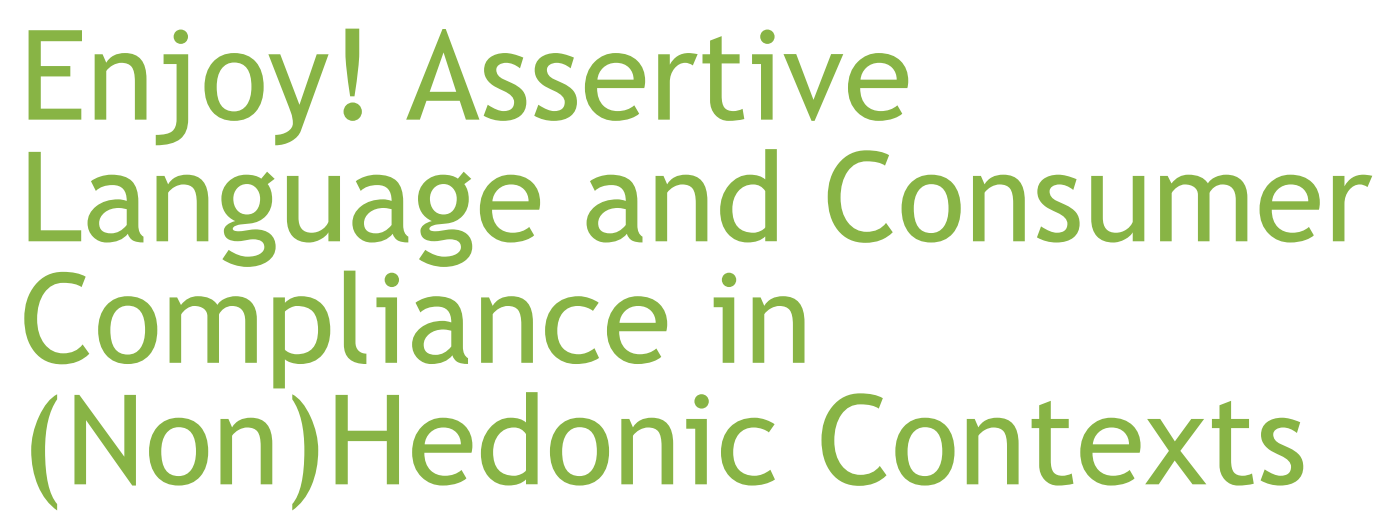

Ann Kronrod, Tel-Aviv University

Amir Grinstein, Ben-Gurion University of the Negev Luc Wathieu, ESMT 


\title{
Abstract
}

\section{Enjoy! Assertive Language and Consumer Compliance in (Non)Hedonic Contexts}

\author{
Author(s): Ann Kronrod, Tel-Aviv University \\ Amir Grinstein, Ben-Gurion University of the Negev \\ Luc Wathieu, Ferrero Chair in International Marketing, ESMT*
}

This paper is concerned with the tension between consumer persuasion and freedom of choice. We study how assertive language (as in the slogan Just do it!) affects consumer compliance in hedonic vs. utilitarian contexts. Previous literature consistently claimed that forceful language would cause reactance and decreased compliance. However, we find in four studies that assertive persuasion is effective in contexts involving hedonic goods and hedonically framed utilitarian goods. Our hypotheses emerge from sociolinguistic research and confirm the relevance of linguistic research in consumer behavior.

Keywords: assertive message, consumer compliance, hedonic consumption, utilitarian consumption, forceful language, persuasion, freedom of choice; reactance

J EL Classification: D18, M37 


\section{INTRODUCTION}

Consumers are often exposed to forceful messages and imperative slogans such as Nike's Just do it! , Sprite's Obey your thirst! or U.S. Airways' Fly with US! However, common wisdom suggests that such assertive phrasing should cause a reactance against the message, because it conveys someone else's will instead of encouraging free choice. Indeed, this intuition is supported by research findings across a variety of domains (e.g., Dillard and Shen 2005; Quick and Considine 2008). Persuasive communication in practice often favors non-assertive language, as in Microsoft's seemingly more engaging slogan Where do you want to go today?

The purpose of this paper is to understand the comparative effectiveness of assertive and non-assertive language in consumer contexts - where persuasion grapples with freedom of choice. This project potentially brings additional credentials to cognitive and socio-linguistics foundations in consumer research (e.g., Luna and Peracchio 2001; Phillips and McQuarrie 2009; Puntoni, de Langhe, and Van Osselaer 2009; Zhang and Schmitt 2004).

When one attempts to bring someone else to do something, the context is one where a directive (Searle 1969) potentially threatens individual freedom of choice (Brown and Levinson 1987). Reactance Theory (Brehm 1966) predicts lower compliance with assertive messages due to a perceived threat on freedom of choice. This suggests the need to avoid assertive claims in persuasion. However, we argue that the effect of assertive messages is not negative in all contexts. In particular, we focus on the effect of assertiveness in a directive message on consumer compliance in hedonic vs. non-hedonic (utilitarian) contexts. Hedonism is prevalent in consumption and often constitutes a relevant contextual factor to understand consumer behavior (e.g., Chaudhuri and Holbrook 2001; Voss, Spangenberg, and Grohmann 2003). However, thus far no attention was given to the moderating role of hedonic contexts in the relationship between message assertiveness and consumer compliance. We contend that the role of hedonic contexts can be informed by insights from socio-linguistic research on the effects of mood and happiness on the acceptance of direct language (e.g., Forgas 1999a, 1999b). Consistent with these insights, we propose that assertive messages in hedonic contexts are less likely to activate the freedomreactance tension and are actually able to elevate compliance.

We start with a literature review on reactance and compliance, hedonic vs. non-hedonic contexts, and the effect of assertive language. We next introduce four testable hypotheses and provide evidence from four studies. Study 1 demonstrates the phenomenon of higher compliance to an assertive message in a hedonic (spa), but not in a utilitarian (computer) context. It also supports the hypothesis that higher compliance is due to lower reactance toward assertive language in hedonic contexts. Study 2 replicates the results in reference to a different hedonic context (a restaurant) and a less immediate utilitarian domain (environmental protection behavior). Study 3 generalizes the findings to situations in which utilitarian products are presented in a metaphorical hedonic framing. Finally, study 4 approaches the relationship between hedonic context and assertive message from an inverted point of view, showing that when an assertive message is encountered, the target product is perceived as more hedonic than the same product promoted with a non-assertive message. The last section concludes and suggests further research directions. 


\section{ASSERTIVE MESSAGES AND CONSUMER REACTANCE}

Brehm (1966) developed Reactance Theory to describe the psychological state in which people find themselves when free individual behavior is challenged by constraints. When freedom of behavior or freedom of choice is violated or limited, individuals tend to reject compliance in order to restore freedom.

Research in consumer behavior has identified several effects of freedom of choice on perceptions, attitudes and behavior (e.g., Chernev 2006; Lancaster 1990; Wathieu et al. 2002). For example Berger, Draganska, and Simonson (2007) show that the variety offered by a brand serves as a quality cue and influences brand choice. In a similar vein, Schlosser and Shavitt (2009) find that when consumers can make choices regarding the information they receive about a product, their evaluation of the product and associated company is more positive. Further, psychologists studying self-determination (e.g., Deci and Ryan 2002) have reinforced the notion that constraints on choice yield reactance.

Beyond concrete limitations of choice, Brown and Levinson (1987) have suggested that any directive phrase is a threat to the hearer's freedom, being perceived as an external force that is meant to influence choice. This suggests that direct language should cause reactance and limit compliance. There is a vast literature to demonstrate reactance in response to persuasion (e.g., Edwards, Li and, Lee 2002; Quick and Considine 2008). Limits on promotions and products accessibility are also known to cause reactance (e.g., Inman et al. 1997).

Adding another layer of refinement, research in socio-linguistics has consistently found that indirect (less assertive) requests are less face-threatening than direct (more assertive) requests and yield higher rates of compliance with the message (Dillard et al. 1997; Gibbs 1986; Holtgraves 1991; Wilson and Kunkel 2000). To the contrary, forceful language has been repeatedly found to act as a threat to consumers' freedom of choice that should depress compliance (e.g., Dailey 2004; Dillard and Shen 2005; Quick and Considine 2008).

\section{THE ROLE OF HEDONIC CONTEXT AND FRAMING}

The studies cited above contributed significantly to the development of Reactance Theory but they did not identify contextual moderators of reactance. To find conditions under which forceful language might not elevate reactance, we start from observations made in the mood literature, which suggest that people in positive mood are prone to use a more direct and assertive language. Most notably, a series of studies reported by Forgas (1999a, 1999b) demonstrated that mood affects the phrasing of requests. He has found people in a negative mood to be more careful, and to formulate more polite and elaborate requests, whereas people in a positive mood were more direct and less elaborate in formulating requests. Bloch (1996) also shows that positive emotions are expressed in a more direct language. Research has further found that happier people are more prepared for bold actions and decisions (e.g., Qiu and Yeung 2008).

Based on this notion that positive mood tends to generate assertive language, it should make sense that assertiveness in persuasive messages will be effective in hedonic consumption contexts, where alternatives involve attributes capable of inducing emotional and affective experiences, sensual pleasure, fantasy and/or fun (Adaval 2001; Dhar and Wertenbroch 2000; Kivetz and Simonson 2002a). Indeed, hedonic contexts are likely to activate positive mood and inhibit the 
propensity for consumers to interpret persuasive communications in terms of restrictions of freedom.

If this is the case then we should expect an interaction between context (hedonic vs. nonhedonic) and message assertiveness (assertive vs. non-assertive). Compliance to an assertive message in non-hedonic contexts should be lower than compliance to a non-assertive message, due to reactance elevated by the forceful language of the assertive phrasing. Conversely, higher compliance with a more assertive message is expected in hedonic contexts, due to reduced reactance. The following hypotheses capture our main prediction and its explanation in terms of reactance:

H1: Assertive (non-assertive) messages yield higher compliance intention in hedonic (nonhedonic) contexts.

\section{H2: Assertive (non-assertive) messages imply lower reactance in hedonic (non-hedonic)} contexts.

The inhibition of reactance through positive mood suggests a broader scope for assertive persuasion. Indeed, it is plausible that the effects observed in hedonic consumption contexts could also be delivered through merely associating hedonic states with contexts normally viewed as utilitarian (Clarkson, Hirt, Chapman, and Jia, forthcoming). For example, when a credit card is framed as access to happy consumption (UBS), or tires are framed as opening the road to exciting adventures (GT). We call this "hedonic framing." Thus, we put forth the following hypothesis:

\section{H3: Following the use of a hedonic (non-hedonic) framing for a utilitarian product, compliance is higher with an assertive (non-assertive) message.}

It has been previously shown that language affects perceptions and attitudes (e.g., Luna, Peracchio, and Dolores 2003) and thus we should expect - as a correlate that reinforces our key prediction - that consumers encountering an assertive phrasing should infer that the product being promoted is more hedonic. This inverted effect can be formulated as follows:

H4: Consumers perceive products promoted with more (non)assertive language as (less) more hedonic.

\section{STUDY 1: MESSAGE ASSERTIVENESS AND COMPLIANCE}

Study 1 was designed to investigate the hypothesis that compliance with an assertive message in hedonic contexts would be higher than with a non-assertive message, while the opposite would be true in a utilitarian context. Also, by employing various phrasings for assertive and non-assertive messages, study 1 intended to rule out possible alternative explanations based on contextual perceptions of assertiveness (e.g., one might argue that when consumers read you must in an advertisement they do not perceive the phrase as an assertive directive, but rather as a friendly advice).

Method

We used a survey to identify items that people would view primarily as hedonic or utilitarian, following Khan and Dhar (2006). Fourteen participants rated 24 items on a nine-point scale $(1=$ 
"utilitarian," 9 = "hedonic"). The list included extremely hedonic products, like a restaurant or icecream and extremely utilitarian examples, such as floor cleaning soap or toothpaste. More ambiguous items, such as a book or an apple were viewed as both hedonic and utilitarian. All products and services used in the following studies were included in the survey. Following Strahilevitz and Myers (1998), we described a utilitarian or a necessary item as one that is mainly desired to fulfill a basic need or to accomplish a functional or practical task, and we defined a hedonic or a luxury item as one primarily desired for pleasure, fantasy and fun.

We selected two products representing the extreme cases found on the survey: spa as a hedonic product and computer as a utilitarian one. Two printed ads were prepared, one featuring a spa and the other a computer. The ads contained a short description of the advertised product and a promotion message.

Each participant ( $N=160$ undergraduate students) received a printed ad which belonged to one of the four conditions in our design. Following the ad appeared a short questionnaire examining purchase intention (adapted from Chandran and Morwitz (2005)), a manipulation check to make sure that the advertisements were understood correctly, reactance to stimulus (adapted from Hong and Page (1989)) and two questions examining perceived degree of obligation in the phrasing of the ad (all items were on a seven-point scale).

\section{Results and Discussion}

Reliability of the purchase intention measure was $\alpha=.92$, which is similar to the reliability $(\alpha=.89)$ reported in Chandran and Morwitz (2005). Reliability for the reactance to stimulus measure was $\alpha=.79$, which is similar to Hong and Page's (1989) reactance scale reliability $(\alpha=$ .74). Finally, reliability for the perceived obligation measure was $\alpha=.90$.

Consistent with our prediction in $\mathrm{H} 1$, a 2-Way ANOVA showed a significant interaction between product (computer vs. spa) and assertiveness (assertive vs. non-assertive message) $(F(1$, $158)=4.86, p=.029$ ) (see figure 1 ). We find that compliance intention in a hedonic product context is higher for an assertive message than for a non-assertive message, while the opposite holds (but not significantly) in a utilitarian product context $\left[M_{\text {spa-assertive }}=3.37\right.$ and $M_{\text {spa-non-assertive }}=$ $2.6 ; F(1,158)=4.7, p=.03$ and $M_{\text {computer-assertive }}=2.6$ and $M_{\text {computer-non-assertive }}=2.9 ; F(1,158)=.835$ $p>$.05]. 2-Way ANOVA which examined the effect of assertiveness in hedonic and utilitarian contexts on reactance produced a significant interaction $(F(1,158)=4.2, p=.04)$, supporting our reactance-based explanation for this effect, predicted in $\mathrm{H} 2$. We find that reactance in a hedonic product context is lower for an assertive message than for a non-assertive message, while the opposite (though not significantly) holds in a utilitarian product context $\left[M_{\text {spa-assertive }}=2.8\right.$ and $M_{\text {spa- }}$ non-assertive $=3.93 ; F(1,158)=4.8, p<.009$ and $M_{\text {computer-assertive }}=3.05$ and $M_{\text {computer-non-assertive }}=3.55$; $F(1,158)=3.16 p>.05]$.

Mediation analysis. We followed Baron and Kenny's (1986) approach to examining the mediating role of reactance in the effect of assertive language on compliance within hedonic and non-hedonic contexts. Including reactance as a covariate in an ANCOVA model caused the previously significant effect of assertive language on purchase intention to become non-significant $(F(1,154)=2.6, p=.11)$, while the effect of the reactance covariate was significant $(F(1,154)=$ $4.9, p<.001)$. These results support our hypothesis that reactance serves as a mediator for the effect of (non)assertive language in (non)hedonic contexts. 
Figure 1: The Effect of Message Assertiveness on Compliance in Hedonic and Utilitarian Contexts (Study 1)

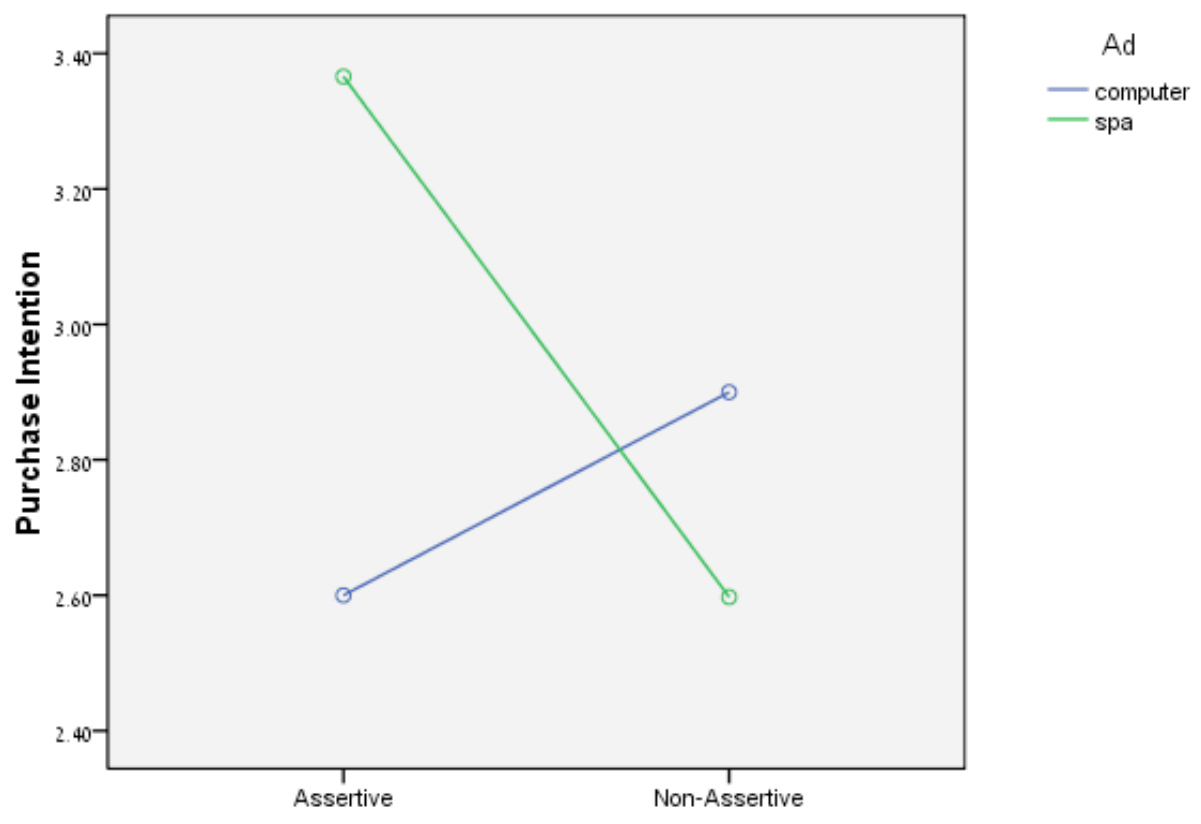

Effect of Specific Words. When a linguistic issue is tested it is important to verify that the effect is not an outcome of a specific wording. Therefore several alternative formulations were prepared for each assertiveness level. The assertive message contained You must go / You should go / Go to the spa (order a computer)! The non-assertive message contained It's worth going / You can go / Would you like to go to the spa (order a computer)? The phrasings were randomly assigned, so that each phrasing was given to approximately 25 participants. In a confounding check we ran a 1-way ANOVA to compare the three assertive and non-assertive formulations on perceived degree of obligation in the phrasing of the ad. We found no significant difference between the various formulations within the assertive, as well as within the non-assertive phrases. However, a significant difference $(t=2.45, p=.015)$ was found between perceived obligation of assertive and non-assertive phrases. This result implies that while various (non)assertive phrasings were equally perceived as (non)assertive, the difference between assertive and non-assertive phrasings was well comprehended by our participants.

Literal meaning of "Must". It is possible that when respondents read the assertively phrased message they did not understood it as an obligating directive, but rather as an advice (as in You must try this cake, it is wonderful!). In other words, it is plausible that "must" does not really mean "must" in a hedonic context. We conducted an Independent Samples T-test analysis to compare the means of reported perceived obligation by the two groups which encountered an assertive message in the hedonic and utilitarian contexts. Our analysis showed no significant difference between the groups in terms of perceived degree of obligation. However, a T-test comparing perceived obligation of assertive phrases vs. non-assertive phrases yielded a significant difference between the assertive and non-assertive formulations, across both contexts $(t=2.45, p=.015)$. These results rule out the explanation that comprehension of assertive messages in hedonic contexts is non-literal and differs from that in utilitarian contexts. 


\section{STUDY 2: HEDONIC VS. ENVIRONMENTAL COMPLIANCE CONTEXTS}

Study 2 replicates the results of study 1 with stimuli that refer to different contexts. For the nonhedonic context, we consider an activity of environmental responsibility (recycling), which implies less immediate (more abstract) non-hedonic consequences and should be associated with greater reactance than computer when assertive language is used (e.g., Lord 1994). The hedonic context stimulus is a restaurant, a more unambiguously hedonic good than the spa.

Method

A short questionnaire was prepared. It included (1) a short introduction and (2) a message which was one of a 2 (assertive vs. non-assertive) by 2 (hedonic vs. non-hedonic context) design. For the hedonic context we chose "good restaurant" and for the non-hedonic context we used "recycling plastic containers." The messages ran: "You must (It's worth to) spoil yourself in a good restaurant and "You must (It's worth to) recycle plastic containers."

The questionnaire contained the measure of compliance intention adapted from Chandran and Morwitz (2005) and the reactance measure adapted from Hong and Page (1989). Hundred and eight undergraduate students received the questionnaire and filled it out voluntarily.

Results and Discussion

Reliability of the compliance intention measure was $\alpha=.88$ and of the reactance to stimulus measure $\alpha=.90$. A 2-way ANOVA was conducted to detect differences in compliance intention as an effect of message assertiveness and context. As expected, the analysis revealed no significant main effects for context (hedonic/non-hedonic) or assertiveness.

Consistent with $\mathrm{H} 1$ a significant interaction between message assertiveness and context was found $(F(1,104)=10.8, p<.001)$. While the recycling message was significantly better able to induce compliance intention when less assertive, the reverse was (marginally) true in the hedonic context (see figure 2) $\left[M_{\text {restaurant-assertive }}=2.6\right.$ and $M_{\text {restaurant-non-assertive }}=2.3 ; F(1,104)=2.49, p<.10$ and $M_{\text {recycling-assertive }}=1.9$ and $\left.M_{\text {recycling-non-assertive }}=2.5 ; F(1,104)=10.7 p<.001\right]$.

We found a significant negative correlation between reactance to stimulus and compliance intention $(r=-.454, \mathrm{p}<.001)$. A 2 -way ANOVA to analyze reactance to stimulus as an effect of message assertiveness and context revealed no significant main effect for context or for assertiveness on reactance. A significant interaction between message assertiveness and context was found $(F(1,104)=4.59, p=.036)$, supporting the prediction that while in a hedonic context reactance is lower with an assertive message, reactance to assertiveness is higher in the recycling context. We find that reactance in a hedonic product context is lower for an assertive message than for a non-assertive message, while the opposite holds in the recycling context $\left[M_{\text {restaurant-assertive }}=\right.$ 1.95 and $M_{\text {restaurant-non-assertive }}=2.55 ; F(1,104)=6.8, p=.013$ and $M_{\text {recycling-assertive }}=2.7$ and $M_{\text {recycling- }}$ non-assertive $=1.7 ; F(1,104)=15 p<.000]$. 
Figure 2: The Effect of Message Assertiveness on Compliance in Hedonic and Non-Hedonic (Environmental) Contexts (Study 2)

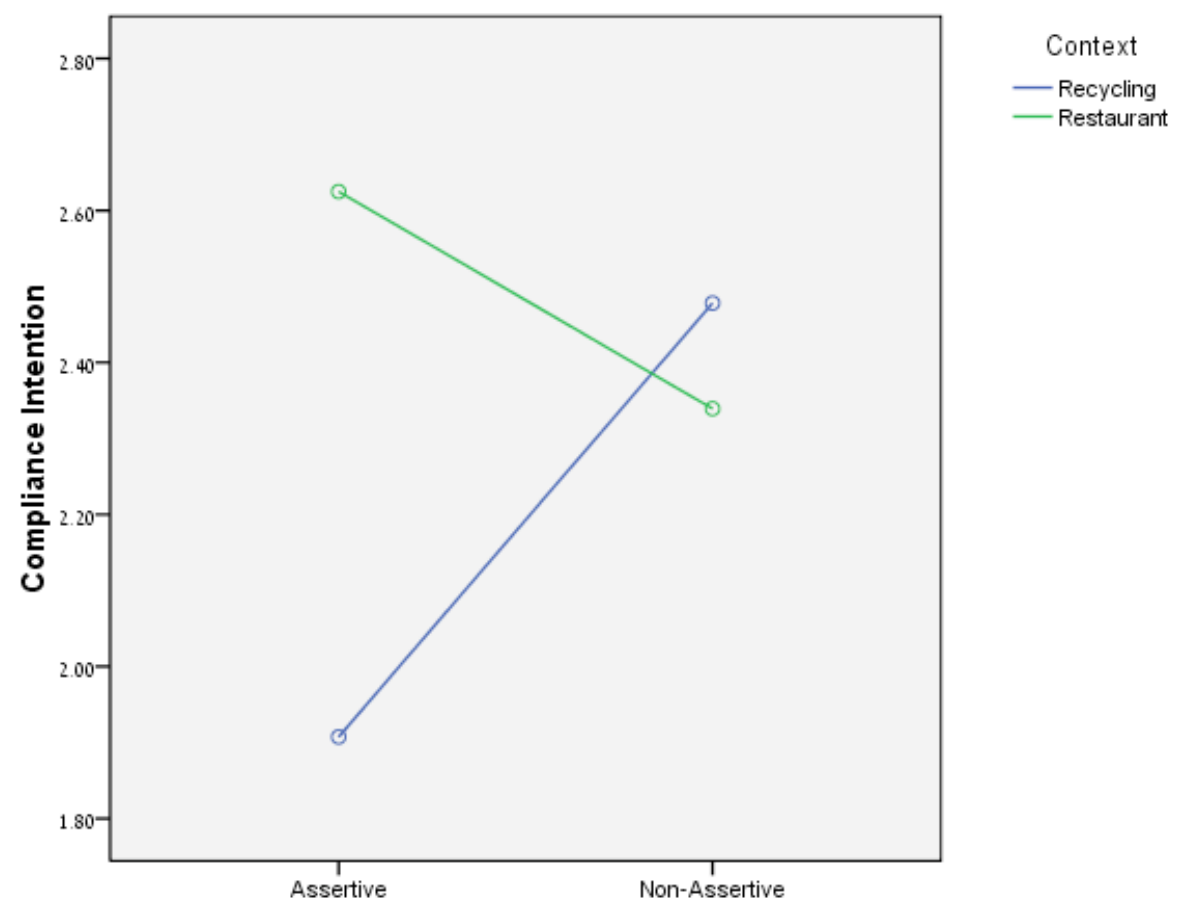

Gender Differences: Previous research on reactance showed gender differences revealing higher reactance for males (e.g., Woller, Buboltz, and Loveland 2007). Independent Sample T-tests comparing males and females revealed no significant differences in compliance intention, but males $(N=48)$ reported higher reactance to stimuli than females $(N=54)(F(1,102)=5.38, p=.022)$.

\section{STUDY 3: THE EFFECT OF HEDONIC FRAMING}

The purpose of this study is to explore the effect of message assertiveness on consumer compliance in situations where utilitarian products and services are advertised in a hedonic vs. utilitarian framing. Based on $\mathrm{H} 3$, we expect that mere hedonic framing can cause higher compliance to an assertive message.

Method

Two real-world advertisements were chosen for the experiment. Both advertisements promoted business services. However, one advertisement, promoting a consulting company, was giving a hedonic framing to this utilitarian service by means of a figurative description and an emotional appeal (a flight to the moon) while the other advertisement, promoting a telecommunications company, used a plain photograph of a business-dressed staff in an office. Both target services received a similar utilitarian score of 2 (telecommunications) and 2.2 (consulting) in our pretest.

Assertiveness was manipulated by editing the directive message featured in each ad to include either assertive or non-assertive phrasing. We used several assertive and non-assertive 
phrasings. For example, assertive phrases were you should count on us / count on us and nonassertive phrases were you can count on us / why not count on us? Nothing else was changed in the advertisements. Overall, the idea was to employ real assertive phrases used in real advertisements with only slight adjustments for purpose of experimental manipulation. Eighty undergraduate students were exposed to one of the advertisements and filled a questionnaire examining purchase intention adapted from Chandran and Morwitz (2005).

Results and Discussion

No main effect was found for assertiveness level or framing on purchase intention. As predicted in $\mathrm{H} 3$, a significant interaction was found between context and assertiveness level in their effect on purchase intention $(F(1,76)=4.03, p=.048)$ (see figure 3 ). Consistent with our previous studies, it was found that in hedonic framing an assertive message yielded significantly higher purchase intention, while in non-hedonic contexts a non-assertive message yielded marginally higher purchase intention $\left[M_{\text {moon-assertive }}=5.2\right.$ and $M_{\text {moon-non-assertive }}=3.8 ; F(1,76)=6.19$, $\mathrm{p}=.018$ and $M_{\text {telecommunications-assertive }}=4.02$ and $M_{\text {telecommunications-non-assertive }}=4.67 ; F(1,76)=1.51, p$ $<.10]$. This result supports $\mathrm{H} 3$, which posited that even in the context of utilitarian products, a hedonic framing could boost the ability of assertive messages to generate compliance.

Figure 3: The Effect of Message Assertiveness on Compliance in Hedonic and Utilitarian Framing (Study 3)

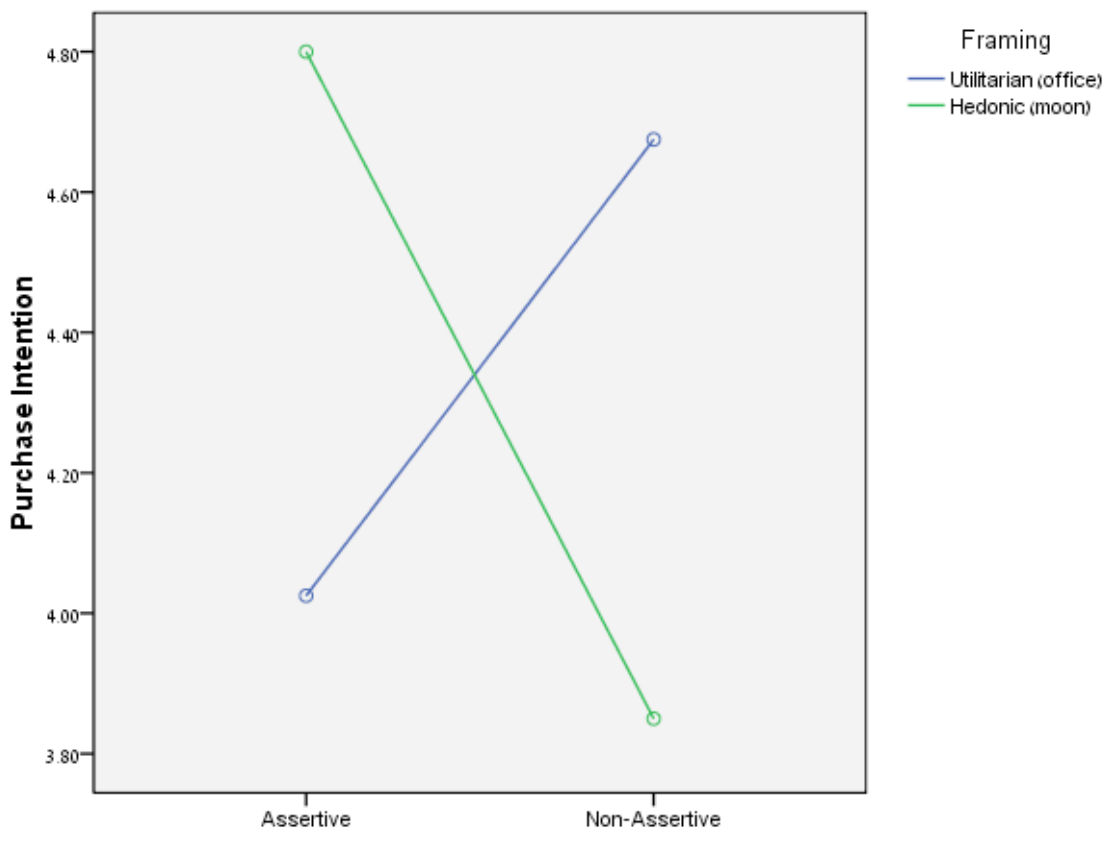

STUDY 4: INVERSE EFFECT

The purpose of study 4 was to test our key prediction in an inversed direction. Relating to the mounting number of slogans and advertising messages that employ assertive language, we hypothesized (H4) that the presence of assertive language would cause consumers to assume a hedonic consumption context, while a non-assertive message would suggest a utilitarian context. Specifically, we expected non-cued imaginary product names (branded as Quile or Dezlik for example) to be more associated with hedonic consumption after they had been introduced in an assertive message compared to a non-assertive message. 
Method

To examine $\mathrm{H} 4$ we conducted an experiment in which participants had to guess the degree of hedonic or utilitarian character of non-cued imaginary brands after seeing an assertive or a nonassertive message (our experimental paradigm was adapted from Leclerc, Schmitt, and Dubé 1994). Specifically, after reading, for example, "you must try QUILE!" or "you should have a QUILE!" (assertive framing), or "you could try the QUILE" or "Why don't you have a QUILE?" (non-assertive framing), participants were asked to guess what type of product these brands represented, and to judge whether it was a hedonic or a utilitarian product.

In a pretest, 12 judges rated ten imaginary product names on two seven-point scales measuring the degree to which the names possessed a hedonic or a utilitarian connotation $(1=$ "not at all," 7="very much so"). For each name a score was computed as the difference between the hedonic and the utilitarian score. Thus, products which were judged equally high or low on both scales received a zero, which represented a neutral score. Out of the 10 products, four names were chosen. Their ratings ranged around zero with a variance of no more than 2 and inter-rate correlation of no less than .5. This made it possible to ensure that the names of the products would not by themselves affect product perception. The chosen names are: Quile, Iklan, Makikel and Dezlik.

Eight messages were composed, employing an assertive and a non-assertive phrasing for each of the four product names. Each participant $(N=48)$ received a booklet containing four messages (one of the versions for each of the four product names). After reading each message participants were asked to evaluate the products on a hedonic-utilitarian seven-point scale (1-“very utilitarian," 7-“very hedonic").

Results and Discussion

A T-test analysis of the responses revealed significant differences between assertive and nonassertive messages for each imaginary brand, supporting our prediction. Table 1 shows the $t$ values and means for each of the products.

Table 1: Means, T-values and Significance for each of the Four Imaginary Products on a Hedonic-Utilitarian Judgment Task (Study 4)

\begin{tabular}{|r|r|r|r|r|}
\hline Product & $\begin{array}{r}\text { Mean } \\
\text { Assertive }\end{array}$ & $\begin{array}{r}\text { Mean } \\
\text { Non-Assertive }\end{array}$ & T-value & Significance \\
\hline Quile & 5.4 & 4.1 & $T(1,43)=2.6$ & $p=.013$ \\
\hline Makikel & 4.9 & 3.8 & $T(1,43)=2.2$ & $p=.037$ \\
\hline Iklan & 4.5 & 2.7 & $T(1,41)=3.7$ & $p=.001$ \\
\hline Dezlik & 4.7 & 3.5 & $T(1,43)=2.0$ & $p=.049$ \\
\hline
\end{tabular}

These results, showing that the same product is perceived more hedonically following an assertive message, reinforce the linguistic foundations of this work. Not only do hedonic contexts raise expectations for assertive language, but also assertive language yields a psycho-linguistic inference that the context is hedonic. 


\section{GENERAL DISCUSSION}

The phrasing of persuasive messages is critical to achieve influence while leaving consumers with the impression of free choice. Based on insights from socio-linguistics, this paper aimed to support the new prediction that more assertive messages would cause greater compliance in hedonic contexts (when products evoke hedonic consumption benefits or even when utilitarian products are described with hedonic metaphors). So far the literature has ignored the possible role of (non)hedonic context and consistently warned against assertiveness in directive messages, deemed to cause reactance.

An issue of particular methodological importance was to make sure that it was the impact of assertiveness that was context-dependent, not the interpretation of specific phrases as more or less assertive. Thus, we employed various directive phrasings in studies 1 and 4, and tested the potential role of contextual interpretation of the assertive language (e.g., interpretation of "you must" as a gentle advice in hedonic contexts), which was ruled out. Study 3 added external validity to our work as we relied on real advertisements. Moreover, in study 3 we used English ads, while the rest of the studies were in Hebrew. Research on differences in politeness judgment between languages (e.g., Blum-Kulka 1994) suggests that English and Hebrew differ in that aspect, and it was thus important to explore the robustness of the findings over the two languages.

The underlying explanation proposed in this work was that a hedonic situation causes happy feelings and results in the acceptance (and expectation) of a more direct and assertive communication style (Forgas 1999a, 1999b). Similarly, there exists evidence that politeness used in contexts where it is not necessary (over-politeness) has an irritating effect that can cause reactance (e.g., Lakoff and Sachiko 2005) and lower compliance intentions towards non-assertive messages in hedonic contexts. Although some of our theoretical underpinnings are related to good mood, mood was not measured in this work because we wanted to focus on reactance and did not want reactance questions to interfere with mood questions. However, we can rely on previous research in this respect that has already shown the positive effect of hedonic context on mood.

Some alternative explanations for the context-dependent effect of message assertiveness on consumer compliance can be suggested although they don't completely account for our findings.

One might first argue that reactance to persuasive messages in hedonic contexts will generally be lower than in utilitarian contexts because it is easier to generate contrarian thoughts in reference to utilitarian - necessarily more concrete - goods. Also, utilitarian goods evoke consequences that are easier to couch in terms of gains and losses, which makes them prone to risk- or regret aversion (e.g., Dhar and Wertenbroch 2000). This line of reasoning may explain greater reactance towards messages in hedonic vs. non-hedonic goods, and perhaps also greater reactance towards assertive vs. non-assertive phrasing. However, it does not yield specific insights about the interaction between context and phrasing, which has been our focus.

Second, research shows that consumers expect more negative (and less positive) feelings when they indulge without a reason than when they indulge with a reason (Kivetz 2005; Kivetz and Keinan 2006; Xu and Schwartz 2009; Zheng and Kivetz 2009). Committing to a virtuous act or an effort in advance of a hedonic choice licenses the choice of a more self-indulgent option (Khan and Dhar 2006). It is therefore plausible that people struggling with guilt feelings are 
looking for an assertive environment as a way to ease indulgence. This prediction could be supported by evidence that assertive language in a hedonic context reduces guilt. While reactance and guilt are not the same concept, the effect of assertive language on reactance that we have found may reflect an effect on guilt. However, this explanation pertains only to hedonic situations and does not predict the difference between assertive and non-assertive message in non-hedonic situations, where guilt is irrelevant.

A potentially interesting direction for future research is to explore the effect of assertive language in contexts with varying degrees of self-determination. A first step in that direction is found in the work by Fitzsimons and Lehmann (2004) that has shown that recommendations by experts and intelligent agents that contradict the consumer's initially chosen option result in consumers ignoring the agents' recommendations or even intentionally contradicting them.

It would also be interesting to examine the effect of a more assertive phrasing over time, compared to a non-assertive one. We might expect the effect of assertive phrasing to last longer because it is stronger and more emotional (Overall et al. 2009). The most important conclusion we draw from this work is that assertive messages can be efficient, even more efficient than nonassertive ones, as long as they are consistent with consumers' state of mind, as in Burger King's slogan Have it your way!

\section{REFERENCES}

Adaval, Rashmi (2001), "Sometimes it Just Feels Right: The Differential Weighting of AffectConsistent and Affect-Inconsistent Product Information," Journal of Consumer Research, 28(June) 1-18.

Baron Reuben M. and David Kenny A. (1986), "The Moderator-Mediator Variable Distinction in Social Psychological Research," Journal of Personality and Social Psychology, 51(December), 1173-82.

Berger Jonah, Michaela Draganska, and Itamar Simonson (2007), "The Influence of Product Variety on Brand Perception and Choice," Marketing Science, 26(July-August), 460-76.

Bloch, Charlotte (1996), "Emotions and Discourse," Text, 16(3), 323-41.

Blum-Kulka, Shoshana (1994), "Politeness Revisited: Cross-Cultural Perspectives," Pragmatics and Cognition, 2(2), 349-56.

Brehm, Jack W. (1966), A Theory of Psychological Reactance. New York: Academic Press.

Brown, Penelope and Stephen Levinson (1987), Politeness: Some Universals in Language Use. Cambridge: Cambridge University Press.

Chandran, Sucharita and Vicki Morwitz G. (2005), 'Effects of Participative Pricing on Consumers' Cognitions and Actions: A Goal Theoretic Perspective," Journal of Consumer Research, 32(2), 249-60.

Chaudhuri, Arjun and Morris Holbrook B. (2001), "The Chain of Effects from Brand Trust and Brand Affect to Brand Performance: The Role of Brand Loyalty," Journal of Marketing, 65(2), 81-94.

Chernev Alexander (2006), "Decision Focus and Consumer Choice among Assortments," Journal of Consumer Research, 33(1), 50-60.

Clarkson, Joshua J., Edward Hirt R., Austin Chapman D., and Lile Jia (2010), "The Impact of Perception on Executive Control: Does Illusory Fatigue Impair Working Memory Capacity?" Working Paper, The Eleventh Annual Meeting of The Society for Personality and Social Psychology, January 28-30, Las Vegas. 
Deci, Edward L. and Richard Ryan M. (2002), Handbook of Self-Determination Research. Rochester, NY: University of Rochester Press.

Dhar, Ravi and Klaus Wertenbroch (2000), "Consumer Choice between Hedonic and Utilitarian Goods," Journal of Marketing Research, 37(February), 60-71.

Dillard, James P. and Shen, L. (2005). "On the Nature of Reactance and its Role in Persuasive

Health Communication," Communication Monographs, 72(June), 144-68.

Dillard, James P., Steven Wilson R., James Tusing K., and Terry Kinney A. (1997), "Politeness Judgments in Personal Relationships," Journal of Language and Social Psychology, 16(3), 297-325.

Edwards, Steven M., Hairong Li, and Joo-Hyun Lee (2002), "Forced Exposure and Psychological Reactance: Antecedents and Consequences of the Perceived Instrusiveness of Pop-Up Ads," Journal of Advertising, 31(Fall), 83-95.

Fitzsimons, Gavan J. and Donald Lehmann R. (2004), "Reactance to Recommendations: When Unsolicited Advice Yields Contrary Responses," Marketing Science, 23(Winter), 82-95.

Forgas, Joseph P. (1999a), "On Feeling Good and Being Rude: Affective Influences on Language Use and Request Formulations," Journal of Personality and Social Psychology, 76(6), 92839.

Forgas, Joseph P. (1999b), "Feeling and Speaking: Mood Effects on Verbal Communication Strategies," Personality and Social Psychology Bulletin, 25(7), 850-63.

Gibbs, Raymond W. (1986), "What Makes Some Indirect Speech Acts Conventional?” Journal of Memory and Language, 25(April), 181-96.

Holtgraves, Thomas (1991), "Interpreting Questions and Replies: Effects of Face-Threat, Question Form, and Gender," Social Psychology Quarterly, 54(March), 15-24.

Hong, Sung-Mook and Sandra Page (1989), "A Psychological Reactance Scale: Development, Factor Structure and Reliability," Psychological Reports, 64(June), 1323-26.

Inman, Jeffrey J., Anil Peter C., and Priya Raghubir (1997), "Framing the Deal: The Role of Restrictions in Accentuating Deal Value," Journal of Consumer Research, 24(June), 68-79.

Khan, Uzma and Ravi Dhar (2006), "Licensing Effect in Consumer Choice," Journal of Marketing Research, 43(May), 259-66.

Kivetz, Ran (2005), "Promotion Reactance: The Role of Effort-Reward Congruity," Journal of Consumer Research, 31(March), 725-37.

Kivetz, Ran and Anat Keinan (2006), "Repenting Hyperopia: An Analysis of Self-Control Regrets," Journal of Consumer Research, 33(September), 273-82.

Kivetz, Ran and Itamar Simonson (2002a), "Earning the Right to Indulge: Effort as a Determinant of Customer Preferences Toward Frequency Program Rewards," Journal of Marketing Research, 39 (May), 155-70.

Lakoff Robin T. and Sachiko Ide (eds.) (2005), Broadening the Horizon of Linguistic Politeness. (Pragmatics and Beyond New Series, 139). Amsterdam/Philadelphia: John Benjamins.

Lancaster, Kelvin (1990), "The Economics of Product Variety: A Survey," Marketing Science, 9(3), 189-206.

Lord, Kenneth R. (1994), "Motivating Recycling Behavior: A Quasiexperimental Investigation of Message and Source Strategies," Psychology and Marketing, 11(September), 341-59.

Luna, David and Laura A. Peracchio (2001), "Moderators of Language Effects in Advertising to Bilinguals: A Psycholinguistic Approach," Journal of Consumer Research, 28 (September), 284-95.

Luna, David, Laura Peracchio A., and Dolores de Juan María (2003), “The Impact of Language and Congruity on Persuasion in Multicultural E-Marketing," Journal of Consumer Psychology, 13(1-2), 41-51. 
Overall, Nickola C., Garth Fletcher J. O., Jeffry Simpson A., and Chris Sibley G. (2009), "Regulating Partners in Intimate Relationships: The Costs and Benefits of Different Communication Strategies," Journal of Personality and Social Psychology, 96(3), 620-39.

Phillips, Barbara J. and Edward McQuarrie F. (2009), "Impact of Advertising Metaphor on Consumer belief," Journal of Advertising, 38(1), 49-61.

Puntoni, Stefano, Bart de Langhe, and Stijn van Osselaer (2009), "Bilingualism and the Emotional Intensity of Advertising Language," Journal of Consumer Research, 35(October), 1012-25.

Qiu, Cheng and Catherine Yeung W.M. (2008), "Mood and Comparative Judgment: Does Mood Influence Everything and Finally Nothing?" Journal of Consumer Research, 34(September), 657-69.

Quick, Brian L. and Jennifer Considine R. (2008), "Examining the Use of Forceful Language When Designing Exercise Persuasive Messages for Adults: A Test of Conceptualizing Reactance Arousal as a Two-Step Process," Health Communication, 23(September), 48391.

Schlosser Ann E. and Sharon Shavitt (2009), "The Effect of Perceived Message Choice on Persuasion," Journal of Consumer Psychology, 19(July), 290-301.

Searle, John (1969), Speech Acts. Cambridge University Press.

Strahilevitz Michal and John Myers G. (1998), "Donations to Charity as Purchase Incentives: How Well they Work may Depend on what you are Trying to Sell," Journal of Consumer Research, 24(May), 434-47.

Voss, Kevin E., Eric R. Spangenberg, and Bianca Grohmann (2003), "Measuring the Hedonic and Utilitarian Dimensions of Consumer Attitude," Journal of Marketing Research, 40(August), 310-20.

Wathieu, Luc, Lyle Brenner, Ziv Carmon, Amitava Chattopadhyay, Klaus Wertenbroch, Aimee Drolet, John Gourville, A. V. Muthukrishnan, Nathan Novemsky, Rebecca K. Ratner, and George Wu (2002), "Consumer Control and Empowerment: A Primer," Marketing Letters, 13(3), 295-303.

Wilson, Steven R. and Adrianne Kunkel W. (2000), "Identity Implications of Influence Goals: Similarities in Perceived Face Threats and Facework across Sex and Close Relationships," Journal of Language and Social Psychology, 19(2), 195-221.

Woller, Kevin M. P., Walter Buboltz C. Jr., and James Loveland M. (2007), "Psychological Reactance: Examination across Age, Ethnicity and Gender," American Journal of Psychology, 120(Spring), 15-24.

$\mathrm{Xu}$, Jing and Norbert Schwartz (2009), “Do We Really Need a Reason to Indulge?" Journal of Marketing Research, 46(February), 25-36.

Zhang, Shi and Bernd H. Schmitt (2004), "Activating Sound and Meaning: The Role of Language Proficiency in Bilingual Consumer Environments," Journal of Consumer Research, 31(June), 220-8.

Zheng, Yuhuang and Ran Kivetz (2009), "The differential Promotion Effectiveness on Hedonic Versus Utilitarian Products," Advances in Consumer Research, 36, page 565. 





\section{Recent ESMT Working Papers}

\begin{tabular}{|c|c|c|}
\hline & $\begin{array}{l}\text { ESMT } \\
\text { No. }\end{array}$ & $\begin{array}{l}\text { Competence } \\
\text { Center }\end{array}$ \\
\hline $\begin{array}{l}\text { Enjoy! Assertive Language and Consumer Compliance in (Non)Hedonic } \\
\text { Contexts }\end{array}$ & 09-007 & \\
\hline $\begin{array}{l}\text { Ann Kronrod, Tel-Aviv University } \\
\text { Amir Grinstein, Ben-Gurion University of the Negev } \\
\text { Luc Wathieu, Ferrero Chair in International Marketing, ESMT }\end{array}$ & & Technology \\
\hline $\begin{array}{l}\text { ISO 9000: New Form of Protectionism or Common Language in } \\
\text { International Trade? }\end{array}$ & 09-006 & $\begin{array}{c}\text { European } \\
\text { Competitiveness }\end{array}$ \\
\hline $\begin{array}{l}\text { Joseph A. Clougherty, University of Illinois at Urbana-Champaign } \\
\text { Michat Grajek, ESMT }\end{array}$ & & \\
\hline $\begin{array}{l}\text { Demography vs. Context: A Cross-Country Survey of the Willingness to Rely } \\
\text { on Trust in Business Partnerships }\end{array}$ & 09-005 & $\begin{array}{l}\text { Management } \\
\text { and }\end{array}$ \\
\hline $\begin{array}{l}\text { Francis Bidault, ESMT } \\
\text { José R. de la Torre, Florida International University } \\
\text { Stelios H. Zanakis, Florida International University }\end{array}$ & & Technology \\
\hline $\begin{array}{l}\text { Regulation and Investment in Network Industries: Evidence from European } \\
\text { Telecoms }\end{array}$ & 09-004 & $\begin{array}{c}\text { European } \\
\text { Competitiveness }\end{array}$ \\
\hline \multicolumn{3}{|l|}{$\begin{array}{l}\text { Michat Grajek, ESMT } \\
\text { Lars-Hendrik Röller, ESMT }\end{array}$} \\
\hline $\begin{array}{l}\text { Access Regulation and Investment in Next Generation Networks: A Ranking } \\
\text { of Regulatory Regimes }\end{array}$ & 09-003 & $\begin{array}{l}\text { European } \\
\text { Competitiveness }\end{array}$ \\
\hline \multicolumn{3}{|l|}{$\begin{array}{l}\text { Rainer Nitsche, ESMT } \\
\text { Lars Wiethaus, ESMT }\end{array}$} \\
\hline $\begin{array}{l}\text { The Effect of Adversity on Process Innovations and Managerial Incentives } \\
\text { Benoit Dostie, HEC Montréal } \\
\text { Rajshri Jayaraman, ESMT }\end{array}$ & 09-002 & $\begin{array}{l}\text { Management } \\
\text { and } \\
\text { Technology }\end{array}$ \\
\hline $\begin{array}{l}\text { An Empirical Approach to Understanding Privacy Concerns } \\
\text { Luc Wathieu, ESMT } \\
\text { Allan Friedman, John F. Kennedy School, Harvard University }\end{array}$ & 09-001 & $\begin{array}{l}\text { Management } \\
\text { and } \\
\text { Technology }\end{array}$ \\
\hline $\begin{array}{l}\text { Cosmopolitanism, Assignment Duration, and Expatriate Adjustment: The } \\
\text { Trade-Off between Well-Being and Performance }\end{array}$ & 08-011 & Leadership \\
\hline \multicolumn{3}{|l|}{$\begin{array}{l}\text { Luc Wathieu, ESMT } \\
\text { Amir Grinstein, Guilford Glazer School of Business and Management, Ben } \\
\text { Gurion University of the Negev }\end{array}$} \\
\hline $\begin{array}{l}\text { Trust and Creativity: Identifying the Role of Trust in Creativity-oriented } \\
\text { J oint-developments }\end{array}$ & 08-010 & $\begin{array}{l}\text { Management } \\
\text { and }\end{array}$ \\
\hline $\begin{array}{l}\text { Francis Bidault, ESMT } \\
\text { Alessio Castello, Georgia Tech France }\end{array}$ & & Technology \\
\hline Career Entrepreneurship & 08-009 & Leadership \\
\hline $\begin{array}{l}\text { Konstantin Korotov, ESMT } \\
\text { Svetlana Khapova, ESMT Visiting Professor and Associate Professor at VU } \\
\text { University Amsterdam }\end{array}$ & & \\
\hline
\end{tabular}




\section{ESMT}

European School of Management and Technology GmbH

Schlossplatz 1

10178 Berlin

Germany

Phone: +49 (0)30212 31-1279

www.esmt.org 